\title{
EFFECT OF SEVERE PLASTIC DEFORMATION BY HIGH-PRESSURE TORSION ON THE STRUCTURE AND PROPERTIES OF COPPER AND TIN BRONZE
}

\author{
A. V. Stolbovsky ${ }^{*}$, V. V. Popov, E. N. Popova, R. M. Falakhutdinov \\ M. N. Miheev Institute of Metal Physics, Ural Branch of the Russian Academy of Sciences, \\ 18 S. Kovalevskoy St., Ekaterinburg, 620990, Russian Federation \\ *Corresponding author. E-mail: stolbovsky@imp.uran.ru \\ Address for correspondence: ul. S. Kovalevskoy, 18, Ekaterinburg, Russian Federation, 620990 \\ Tel.: +7 34337835 74; fax: +7 3433745244
}

The evolution of the structure of $\mathrm{Cu}-1 \mathrm{Sn}$ tin bronze under severe plastic deformation by high-pressure torsion has been studied and compared with that of commercially pure copper. It is demonstrated that high-pressure torsion of bronze results in much higher strengthening and structure refinement than that of commercially pure copper, as the presence of the doping element in the former promotes the retardation of dynamic recrystallization and relaxation processes. Besides, contrary to copper, which undergoes not only dynamic, but also post-dynamic recrystallization, all the bronze samples studied are stable after the HPT at room temperature, and they do not suffer any changes after unloading and prolonged ageing.

Key words: nanostructuring, nanostructures, severe plastic deformation, high-pressure torsion, grain boundaries, thermal stability, tin bronze, copper.

DOI: $10.17804 / 2410-9908.2017 .5 .013-022$

\section{References}

1. Stolbovsky A.V., Popov V.V., Popova E.N. Structure and thermal stability of tin bronze nanostructured by high pressure torsion. Diagnostics, Resource and Mechanics of materials and structures, 2015, iss. 5, pp. 118-132. Available at: http://dream-journal.org/issues/ 2015-5/2015-5_52.html (accessed: 30.10.2017).

2. $\quad$ Krinitsina T.P., Popova E.N., Sudareva S.V., Romanov E.P., Nikulin A.D., Shikov A.K., Vorobyova A.Y. Natural and artificial aging of bronzes used as matrix in Nb3Sn-base composites. Fizika metallov i metallovedenie, 1991, no. 11, pp. 90-98.

3. Tsubakino H. Discontinuous precipitation in $\mathrm{Cu}-\mathrm{Sn}$ alloy. Metallography, 1984, vol. 17, no. 4, pp. 371-382. DOI: 10.1016/0026-0800(84)90074-0

4. Williams D.B., Butler E.P. Grain boundary discontinuous precipitation reaction. International Metals Reviews, 1981, vol. 26, iss. 1, pp. 153-183. DOI: 10.1179/imtr.1981.26.1.153

5. Suchkov D.I. Med i ee splavy [Copper and its Alloys]. Moscow, Metallurgiya Publ., 1967, pp. 104-176. (In Russian).

6. Degtyarev M.V., Chashchukhina T.I., Voronova L.M., Kopylov V.I. Correlation among strain, hardness, and structure element size in iron and structural steels under various severe plastic deformations. Fizicheskaya mezomekhanika, 2013, vol. 16, no. 6, pp. 71-80. (In Russian).

7. Vishnyakov Ya.D. Defekty Upakovki v Kristallicheskoy Strukture [Stacking Faults in Crystal Structure]. Moscow, Metallurgiya Publ., 1970, 66 p. (In Russian).

8. Popov V.V., Popova E.N., Stolbovskii A.V., Pilyugin V.P., Arkhipova N.K. Nanostructurization of $\mathrm{Nb}$ by high-pressure torsion in liquid nitrogen and the thermal stability of the structure obtained. The Physics of Metals and Metallography, 2012, vol. 113, no. 3, pp. 295-301. DOI: 10.1134/S0031918X1203009X

9. Popov V.V., Valiev R.Z., Popova E.N., Sergeev A.V., Stolbovsky A.V., Kazihanov V.U. Structure and properties of grain boundaries in submicrocrystalline $\mathrm{W}$ obtained by severe 
plastic deformation. Defect and Diffusion Forum, 2009, vol. 283-286, pp. 629-639. DOI: $10.4028 /$ www.scientific.net/DDF.283-286.629

10. Chashchukhina T.I., Voronova L.M., Degtyarev M.V., Pokryshkina D.K. Deformation and dynamic recrystallization in copper at different deformation rates in Bridgman anvils. The Physics of Metals and Metallography, 2011, vol. 111, pp. 304-313. DOI: 10.1134/S0031918X11020049 
Подана в журнал: 25.10 .2017

УДК 669.293:539.89:536.425

DOI: $10.17804 / 2410-9908.2017 .5 .013-022$

\title{
ВЛИЯНИЕ ИНТЕНСИВНОЙ ПЛАСТИЧЕСКОЙ ДЕФОРМАЦИИ МЕТОДОМ КРУЧЕНИЯ ПОД ВЫСОКИМ ДАВЛЕНИЕМ НА СТРУКТУРУ И СВОЙСТВА МЕДИ И ОЛОВЯНИСТОЙ БРОНЗЫ
}

\author{
А. В. Столбовский ${ }^{*}$ В. В. Попов, Е. Н. Попова, Р. М. Фалахутдинов \\ Институт физики металлов им. М.Н. Михеева УрО РАН, \\ 620108, Россия, г. Екатеринбург, ул. С. Ковалевской, 18 \\ *Ответственный автор. Электронная почта: stolbovsky@imp.uran.ru \\ Адрес для переписки: ул. С. Ковалевской, 18, Екатеринбург, 620990, Российская Федерация \\ Телефон: +7 (343) 378-35-74; факс: (343) 374-52-44
}

Выполнено исследование эволюции структуры оловянистой бронзы $\mathrm{Cu}-1 \mathrm{Sn}$ при интенсивной пластической деформации методом кручения под высоким давлением и произведено сравнение с данными, полученными для меди технической чистоты при такой же обработке. Показано, что кручение бронзы под высоким давлением приводит к значительно более высокому упрочнению и измельчению структуры по сравнению с медью технической чистоты, вследствие того, что присутствие легирующего элемента способствует торможению динамической рекристаллизации и релаксационных процессов. Кроме того, в отличие от меди, в которой протекает не только динамическая, но и постдинамическая рекристаллизация, все исследованные образцы бронзы после КВД стабильны при комнатной температуре и не претерпевают каких-либо изменений после снятия нагрузки и при длительном вылеживании.

Ключевые слова: наноструктурирование, наноструктуры, интенсивная пластическая деформачия, кручение под высоким давлением, гранищь зерен, термическая стабильность, оловянистая бронза, медь

\section{1. Введение}

Ранее были проведены исследования по возможностям наноструктурирования оловянистой бронзы состава $\mathrm{Cu}-7,4 \mathrm{Sn}$. Однако такое достаточно большое содержание легирующего элемента не предоставляет возможности адекватно произвести сравнение по влиянию олова, присутствующего в сплаве, с данными, полученными при исследовании чистой меди. При этом большинство исследований нацелено именно на исследование составов, применяемых в промышленности, где содержание олова может превышать $10 \%$ по весу в сплаве, например при производстве композитов или других работ прикладного значения [1]. Известно, что структурное состояние и механические свойства бронзы определяются, главным образом, содержанием в ней олова [3] и с увеличением количества Sn возрастают твердость и прочность сплавов, а пластичность их понижается. При этом работы, посвященные исследованиям бронз с низким содержанием олова, практически не встречаются.

Поэтому в настоящей работе ставились задачи провести сравнительное исследование формирования структуры оловянистой бронзы с меньшим содержанием олова $(\mathrm{Cu}-1 \mathrm{Sn})$ при интенсивной пластической деформации кручением под высоким давлением (КВД) и сравнить полученные результаты с результатами исследования формирования структуры меди технической чистоты. 


\section{2. Материал и методика исследования}

Для исследований использовалась оловянистая бронза, химический состав которой приведен в табл. 1, и медь технической чистоты стандарта М1.

Таблица 1 - Химический состав оловянистой бронзы $\mathrm{Cu}-1 \mathrm{Sn}$

\begin{tabular}{|c|c|c|c|c|c|c|}
\hline $\mathrm{Sn}$ & $\mathrm{Pb}$ & $\mathrm{Fe}$ & $\mathrm{Si}$ & $\mathrm{Ni}$ & $\mathrm{Zn}$ & $\mathrm{Bi}$ \\
\hline 1,05 & $\sim 0,01$ & $\sim 0,001$ & $<0,001$ & $\sim 0,001$ & $<0,001$ & $<0,001$ \\
\hline
\end{tabular}

На образцах оловянистой бронзы после литья и высокотемпературной ковки проводился гомогенизирующий отжиг в вакуумной печи при $800{ }^{\circ} \mathrm{C}$ в течение 1 ч, чтобы исключить влияние дендритной ликвации и выровнять состав по сечению образцов.

При деформации методом КВД использовались цилиндрические образцы диаметром 10 мм и начальной высотой 0,5 мм. Деформирование проводилось в открытых наковальнях Бриджмена диаметром 10 мм, при комнатной температуре на 1, 3 и 5 оборотов при давлении 6 ГПа, с угловой скоростью 0,3 об/мин.

Истинную деформацию $е$ рассчитывали, в соответствии с применяемой в аналогичных исследованиях методикой, например, $[6,8-1]$, как сумму истинной деформации сдвигом и

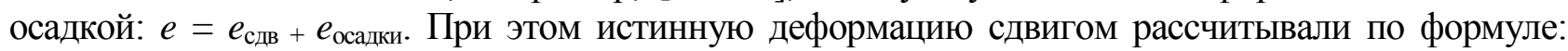
$e_{\text {сдв }}=\ln \left(1+\lambda^{2}\right)^{1 / 2}$, где $\lambda=(\varphi \mathrm{R}) / \mathrm{h}, \lambda-$ деформация сдвигом при кручении, $\varphi-$ угол скручивания в радианах, $\mathrm{h}$ - толщина образца (мм), $\mathrm{R}$ - расстояние от оси вращения (мм). Истинную деформацию осадкой рассчитывали как $e_{\text {осадки }}=\ln \left(\mathrm{h}_{0} / \mathrm{h}_{\mathrm{k}}\right)$, где $\mathrm{h}_{0}$ и $\mathrm{h}_{\mathrm{k}}-$ толщина образца до и после деформации. Отметим, что поскольку степень деформации зависит от расстояния деформируемого участка от оси вращения, то при этом способе ИПД деформация распределена неравномерно по радиусу образца, увеличиваясь от центра к периферии, и, соответственно, структура измельчается неравномерно, и самая мелкая структура формируется в периферийных областях деформируемых дисков. Для корректного сравнения структуры после разной обработки (например, после разного числа оборотов), как правило, рассматривают структуру на середине радиуса образцов.

Оценочные величины истинной деформации на середине радиуса образцов представлены в табл. 2.

Таблица 2 - Расчетная величина истинной деформации, достигаемой при деформировании методом КВД, на середине радиуса образцов

\begin{tabular}{|c|c|c|c|}
\hline Обороты КВД & 1 & 3 & 5 \\
\hline$e$ & $\sim 4,6$ & $\sim 5,9$ & $\sim 6,5$ \\
\hline
\end{tabular}

Структуру исследовали с помощью просвечивающих электронных микроскопов JEM200CX и Philips CM-30. Измерение микротвердости материала после динамического сжатия проводили на приставке к микроскопу Neophot-21 при нагрузке, эквивалентной 40 г, по методике, описанной в работе.

\section{3. Результаты исследования и их обсуждение}

Проведенные исследования показали, что после одного оборота КВД в бронзе формируется градиентная по радиусу диска дисперсная субмикрокристаллическая структура, с преимущественно высокоугловыми разориентировками между кристаллитами.

Поскольку при малых оборотах структура заметно изменяется по радиусу образца, в центральной части, где степень деформации минимальна, средний размер кристаллитов составляет $\sim 200$ нм. С увеличением степени деформации при удалении от центра структура 
измельчается, и на середине радиуса образцов средний размер кристаллитов уменьшается до $\sim 170$ нм (рис. $1 a$ и б), и, наконец, на периферии структура измельчается до среднего размера $\sim 160$ нм.

В центральной части медного образца структура также наименее фрагментирована. Уровень внутренних упругих напряжений не очень высокий, поэтому границы кристаллитов достаточно четкие, почти ровные и тонкие (рис. 1 в и г). Имеются и высокоугловые границы, обрамляющие крупные зерна полиэдрической формы, с низкой плотностью дислокаций. Размеры некоторых из них достигают 400 нм. Но сохраняются и малоугловые границы, о чем свидетельствует плавное изменение контраста в некоторых зернах на темнопольных изображениях.

На электронограммах при этом небольшое количество близко расположенных рефлексов видны на Дебаевских кольцах. Некоторые элекронограммы являются переходными от точечных, характерных для крупнокристаллической структуры, к кольцевым, которые указывают на образование субмикрокристаллической структуры при более высокой степени деформации.

В периферийной части рассматриваемого образца сохраняются, в целом, те же особенности структуры, что и на середине радиуса. Можно только отметить несколько большее измельчение кристаллитов, более равномерную структуру и высокую плотность близкорасположенных рефлексов на Дебаевских кольцах на электронограммах.

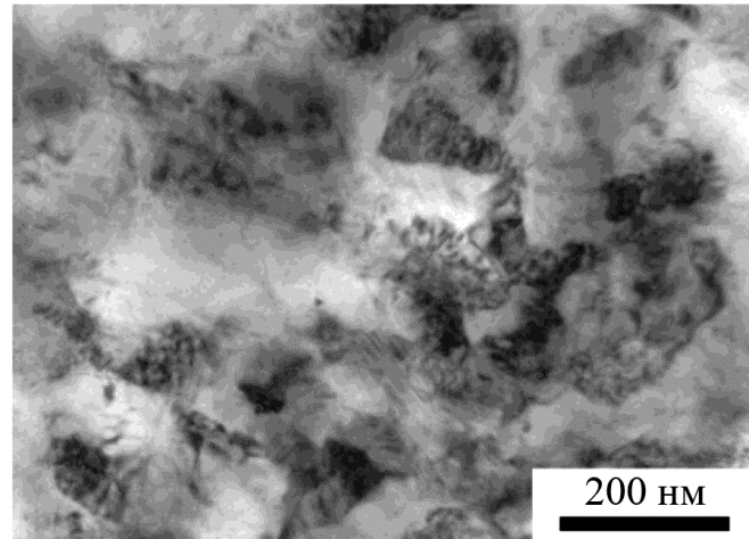

$a$

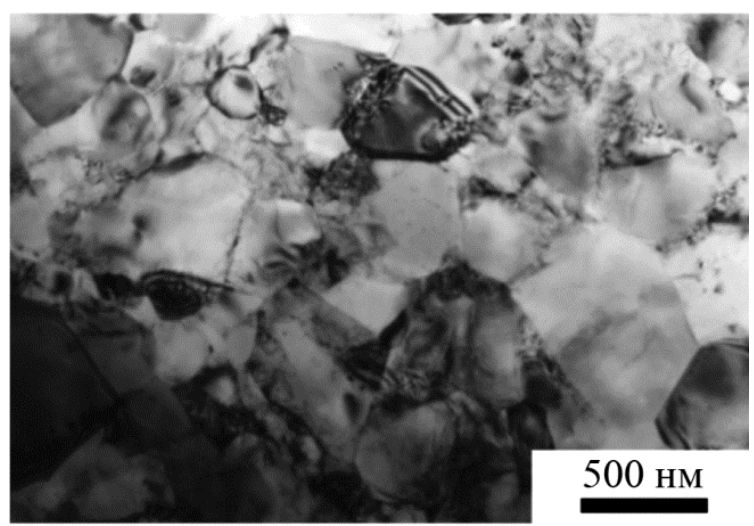

B

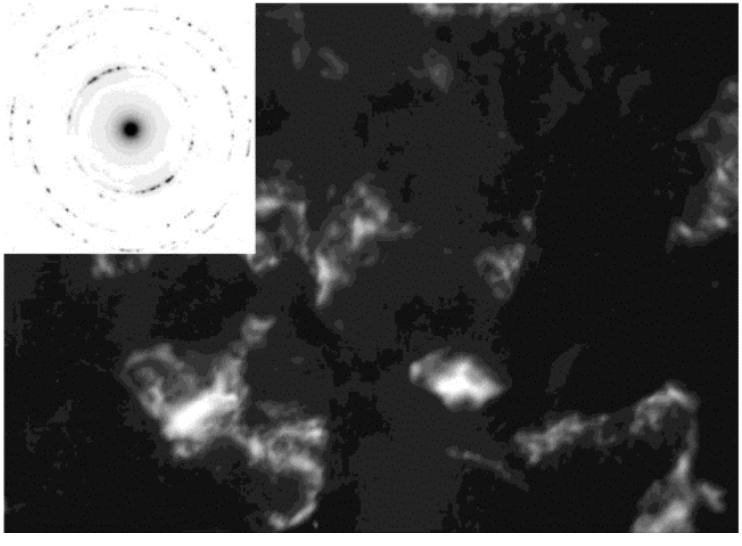

$\sigma$

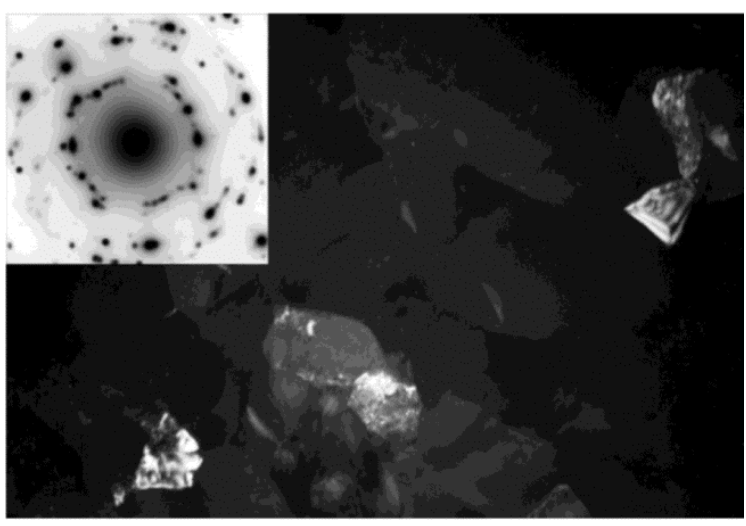

2

Рис. 1. Электронные микрофотографии структуры на середине радиуса образца бронзы $\mathrm{Cu}-1 \mathrm{Sn}(a, \sigma)$ и меди $(b, 2)$ после КВД на 1 оборот; $a$, $в$ - светлые поля; $\sigma, z-$ темные поля и электронограммы 
На некоторых участках сильно фрагментированной структуры (на середине радиуса и на периферии) в кристаллитах виден тонкий полосчатый контраст (например на рис. $1 a$ ). Мы полагаем, что его появление связано с образованием дефектов упаковки и тонких двойниковых прослоек, что в свою очередь обусловлено понижением ЭДУ меди при легировании ее оловом [7].

О градиентном характере структуры свидетельствует также характер изменения микротвердости по радиусу образца (рис. 2). Значения микротвердости составляют $2260 \pm 30$ МПа в центре образца, $2330 \pm 30 \mathrm{MПа} \mathrm{-} \mathrm{на} \mathrm{середине} \mathrm{радиуса} \mathrm{и} 2410 \pm 20 \mathrm{MПа} \mathrm{-} \mathrm{на} \mathrm{краю} \mathrm{образца.}$

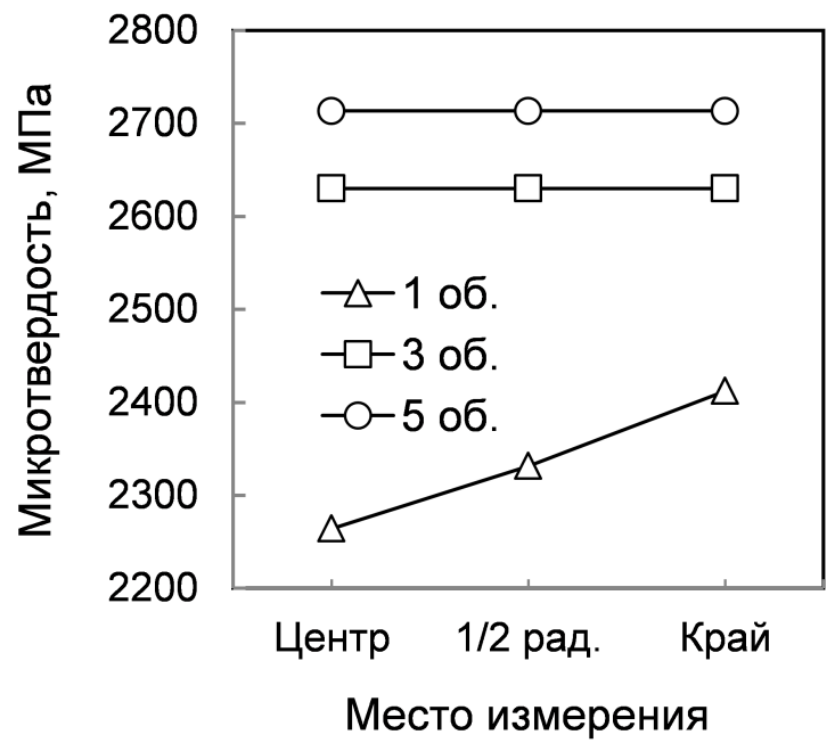

Рис. 2. Изменение микротвердости оловянистой бронзы по радиусу образца после деформирования методом КВД при различном количестве оборотов

С увеличением степени деформации (числа оборотов) КВД происходят одновременно два процесса, а именно, повышение микротвердости и выравнивание ее по радиусу образца (рис. 2). Повышение микротвердости с ростом степени деформации вполне ожидаемо, а тот факт, что структура практически перестает зависеть от положения того или иного участка в плане его удаленности от центра, представляется весьма интересным. Однако это некая общая закономерность, которую мы обнаружили ранее и при КВД ниобия [8], и при деформации этим методом бронзы с более высоким содержанием олова. Мы полагаем, что с ростом степени деформации уровень внутренних упругих напряжений настолько повышается, что они равномерно распределяются по всему сечению, приводя к одинаковому упрочнению и измельчению структуры. С учетом достаточно малых размеров дисков при КВД такое предположение представляется вполне разумным.

Как видно из данных рис. 2, при деформации на 3 оборота микротвердость возрастает до $2630 \pm 40$ МПа и остается практически одинаковой по радиусу образца. Еще более высокое и одинаковое по радиусу значение микротвердости достигается после 5 оборотов КВД, $2710 \pm 40$ МПа.

Интересно отметить, что в бронзе с более высоким содержанием олова (7,4 \% Sn) градиентная по радиусу микротвердость наблюдается при КВД только на 0,25 и 0,5 оборота, в диапазоне 2800-3300 и 3100-3600 МПа соответственно. При КВД высокооловянистой бронзы на 1 оборот уже достигается насыщение и микротвердость остается на уровне 3800 МПа и после 1, и после 5 оборотов. Из этого можно сделать вывод, что с увеличением содержания олова измельчение структуры и упрочнение при КВД происходят значительно более интенсивно. 
Более наглядно интенсивное упрочнение с ростом степени деформации бронзы $\mathrm{Cu}-1 \% \mathrm{Sn}$ демонстрирует рис. 3, на котором значения микротвердости нанесены в зависимости от числа оборотов КВД при комнатной температуре в сравнении с данными, полученными на меди технической чистоты [9].

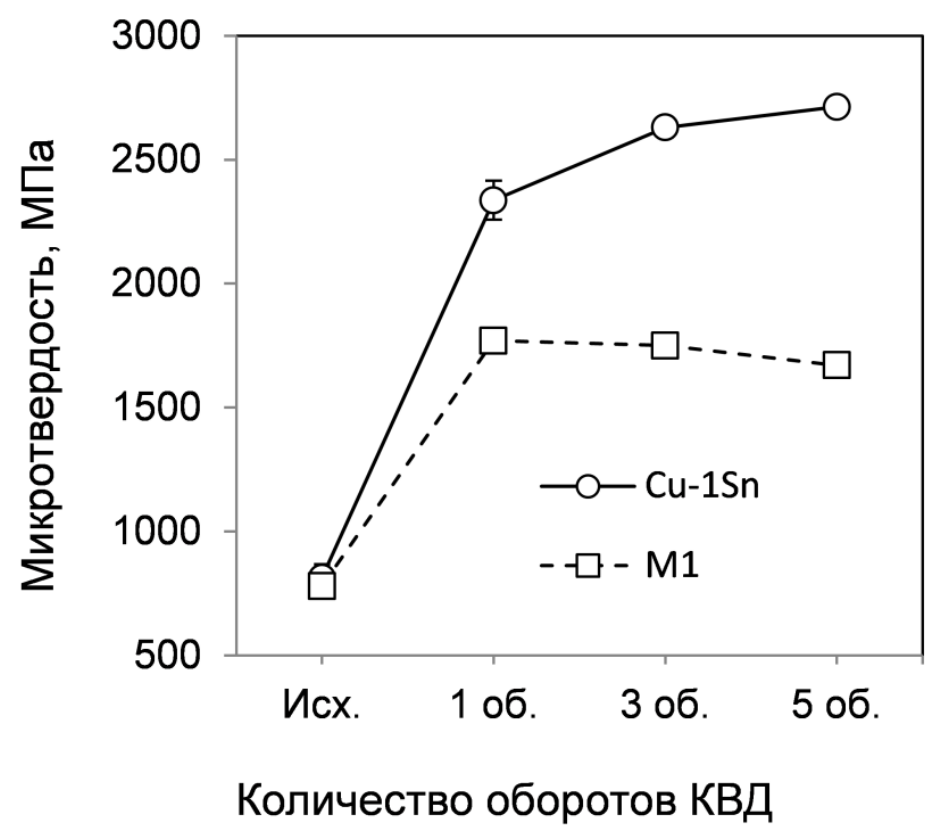

Рис. 3. Изменение микротвердости оловянистой и меди после деформирования методом КВД при различном количестве оборотов (измерения на середине радиуса образцов)

Поскольку в бронзе после КВД на 3 и 5 оборотов микротвердость выравнивается по радиусу образцов, то можно ожидать и достаточно однородной структуры.

Действительно, после 3 оборотов КВД структура оказалась достаточно однородной и для удобства дальнейшего анализа и сравнения мы приводим структуру на середине радиуса образцов (рис. 4). Структура заметно измельчилась по сравнению с представленной выше структурой после 1 оборота КВД. Средний размер кристаллитов в этом состоянии составляет 150 нм. Границы кристаллитов сильно искривлены и не очень четкие, что косвенно свидетельствует о высоком уровне внутренних напряжений и особом «неравновесном» состоянии границ. Контраст на темнопольных изображениях меняется от кристаллита к кристаллиту резко, что указывает на преобладание высокоугловых разориентаций. Практически на всех электронограммах Дебаевские кольца плотно заселены большим количеством рефлексов. Все эти особенности характерны для субмикро- и нанокристаллического состояния, формирующегося под действием КВД. Отметим, что на некоторых участках присутствует тонкий полосчатый контраст, обусловленный образованием дефектов упаковки и двойников (рис. $4 a$ и в). Как отмечено выше, мы связываем его появление с понижением ЭДУ при легировании меди оловом.

Структура меди технической чистоты, деформированной КВД при комнатной температуре на 1-3 оборота, является субмикрокристаллической, со средним размером зерен 240 нм (рис. 4 в и г). В структуре практически отсутствуют крупные рекристаллизованные зерна с низкой плотностью дислокаций, но размер кристаллитов существенно больше, чем в случае бронзы. 


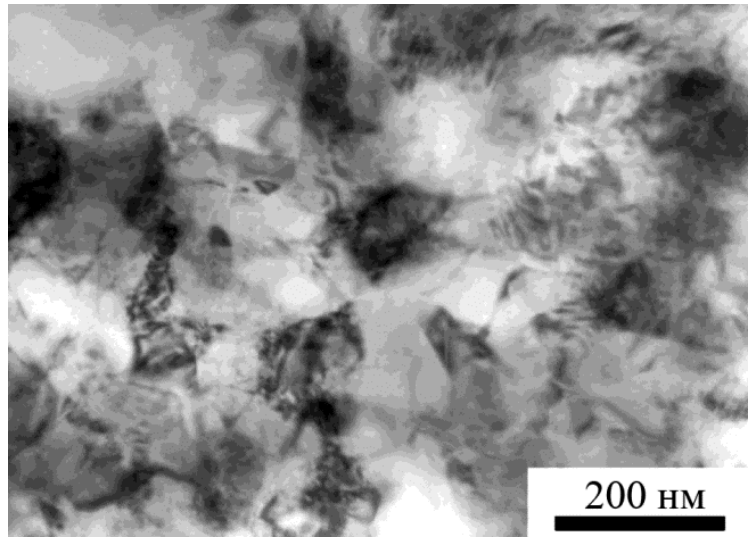

$a$

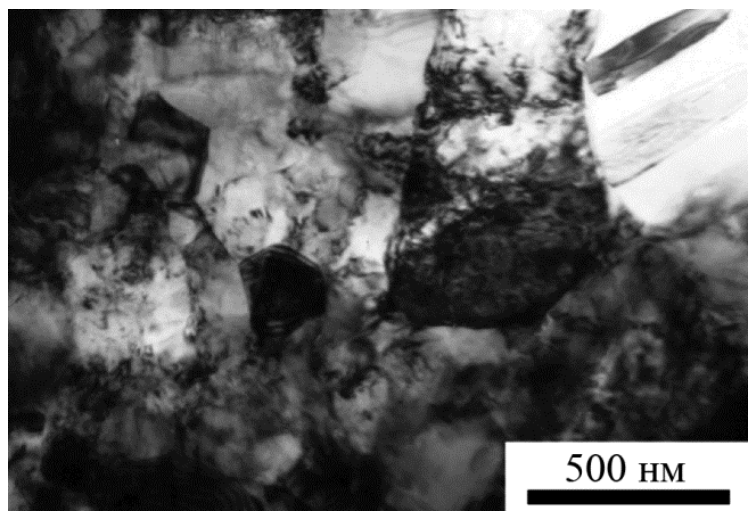

B

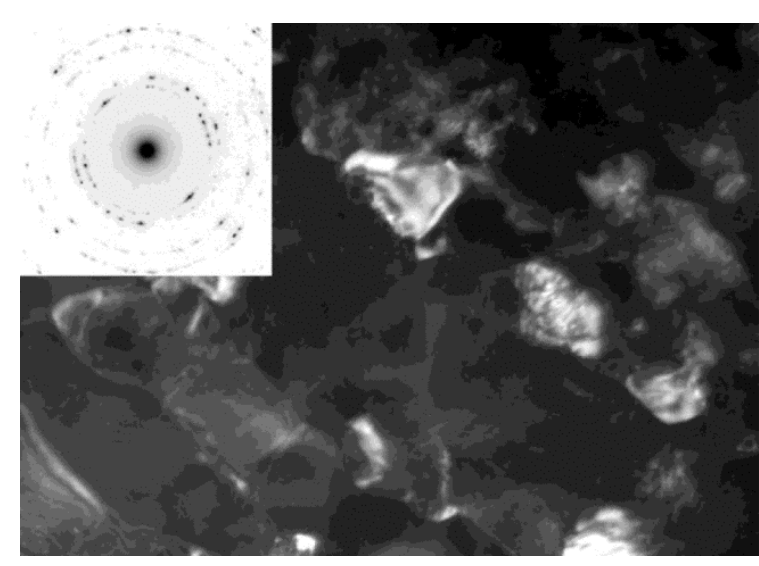

$\sigma$

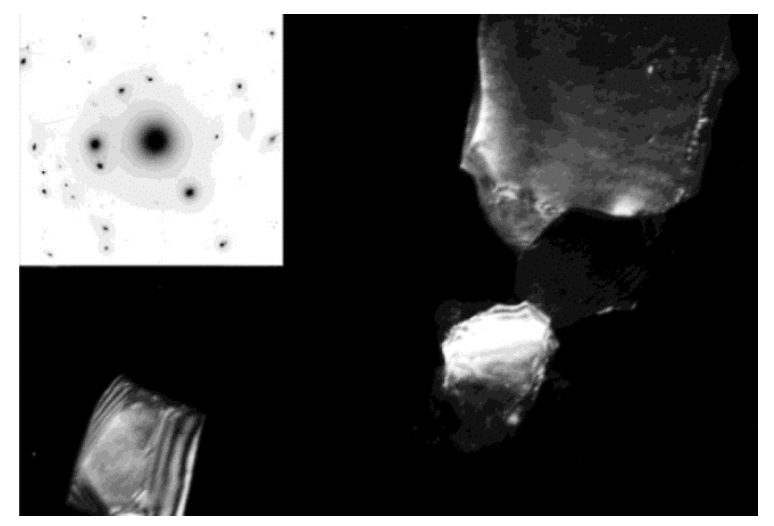

2

Рис. 4. Электронные микрофотографии структуры оловянистой бронзы $(a, \sigma)$ и меди $(6,2)$ после КВД на 3 оборота (на середине радиуса образца); $a$, в - светлые поля; б, г- темные поля и электронограммы

Поскольку при увеличении степени деформации до 5 оборотов микротвердость повышается до $2710 \pm 40$ МПа (рис. 3), то можно было ожидать и дальнейшего измельчения структуры, которая представлена на рис. 5 и в целом очень похожа на структуру после 3 оборотов, но, действительно, она более дисперсна (рис. $5 a$ и б). Средний размер кристаллитов оловянистой бронзы, достигаемый при КВД на 5 оборотов, составляет приблизительно 120 нм. Структура еще более однородна, на Дебаевских кольцах электронограмм еще больше равномерно распределенных рефлексов, а разброс кристаллитов по размерам еще меньше.

В то же время, увеличение степени деформации меди до 5 оборотов приводит к появлению в структуре крупных зерен с низкой плотностью дислокаций, что свидетельствует о начале процессов динамической рекристаллизации (рис. 5 в и г). При этом, как следует из рис. 3, начинается снижение микротвердости.

Таким образом, результаты исследования меди после КВД показывают, что в ней возможно протекание процессов не только возврата, но и динамической рекристаллизации. Следует также отметить, что в отличие от меди технической чистоты, в которой протекает не только динамическая, но и может наблюдаться постдинамическая рекристаллизация [1], все исследованные образцы бронзы после КВД оставались стабильными при комнатной температуре и не претерпевали каких-либо изменений после снятия нагрузки и при длительном вылеживании. 


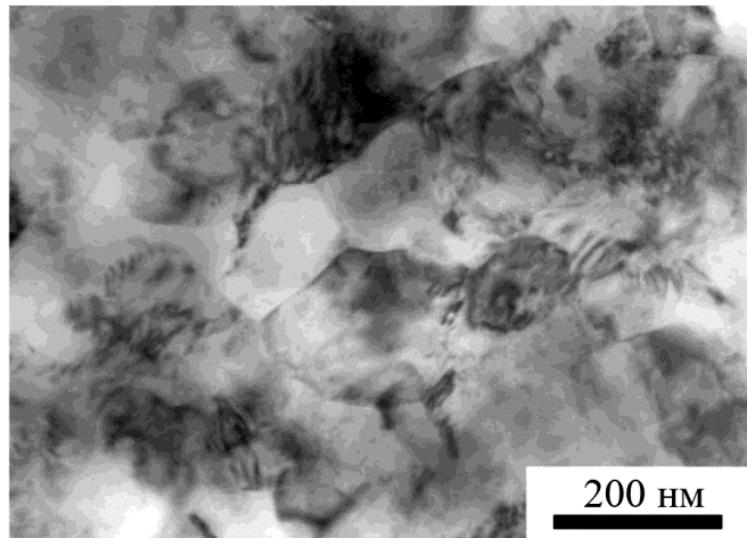

$a$

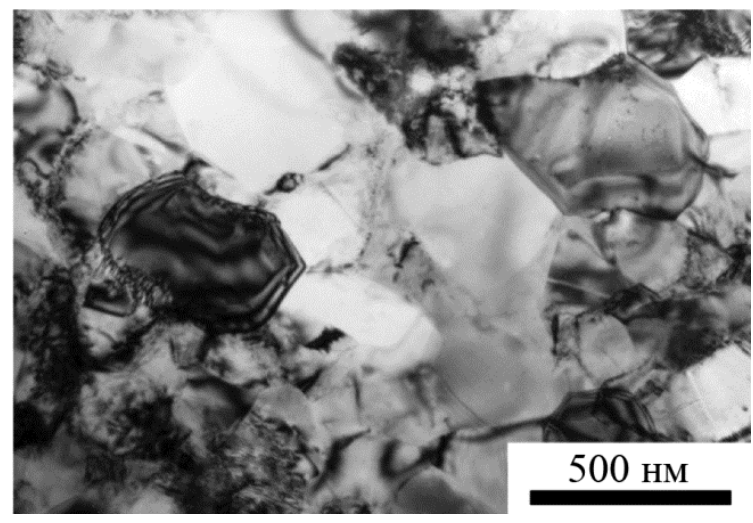

B

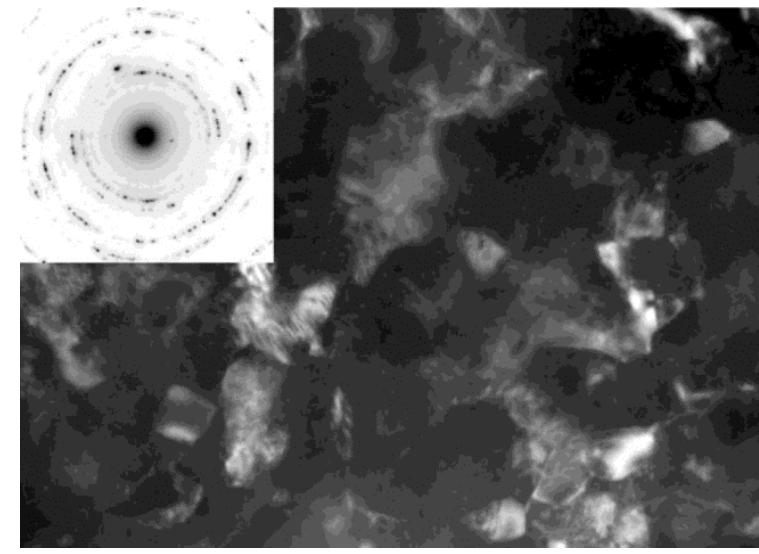

6

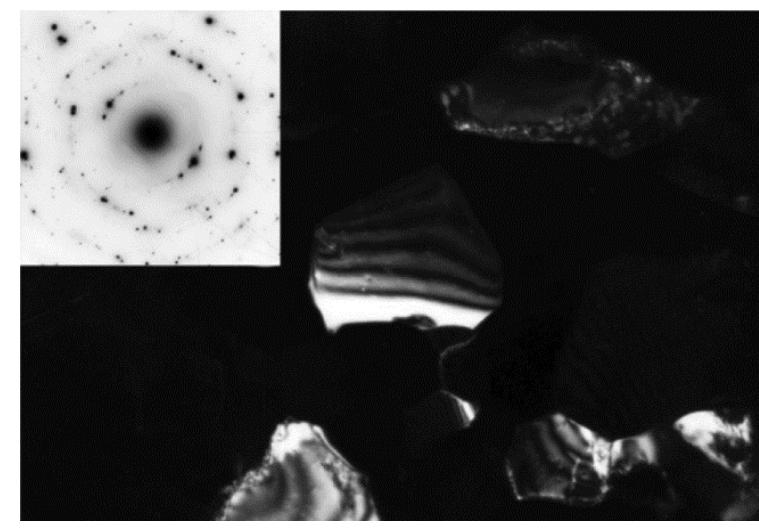

2

Рис. 5. Электронные микрофотографии структуры оловянистой бронзы $(a, \sigma)$ и меди $(6,2)$ после КВД на 5 оборотов (на середине радиуса образца); $a, 8$ - светлые поля, $\sigma$, 2 - темные поля и электронограммы

\section{4. Заключение}

Выполнено исследование эволюции структуры оловянистой бронзы при интенсивной пластической деформации методом кручения под высоким давлением и произведено сравнение с данными, полученными для меди технической чистоты при такой же обработке.

Сравнение влияния кручения под высоким давлением на структуру и микротвердость оловянистой бронзы и меди показывает, что в случае бронзы достигается значительно более высокое упрочнение и измельчение структуры вследствие того, что тормозятся релаксационные процессы. Кроме того, в отличие от меди технической чистоты, в которой протекала не только динамическая, но и постдинамическая рекристаллизация, все исследованные образцы бронзы после КВД остаются стабильными при комнатной температуре и не претерпевали каких-либо изменений после снятия нагрузки и длительном вылеживании.

\section{Благодарность}

Электронно-микроскопическое исследование выполнено на оборудовании изентра коллективного пользования в Испытательном иентре нанотехнологий и перспективных материалов ИФМ УрО РАН. Работа выполнена в рамках государственного задания ФАНО России (тема «Спин», номер госрегистраџии 01201463330), при частичной поддержке Программы фундаментальных исследований УрО РАН (проект 15-9-2-44) и РФФИ (проект 15-03-03103). 


\section{Литература}

1. Stolbovsky A. V., Popov V. V., Popova E. N. Structure and Thermal Stability of Tin Bronze Nanostructured by High Pressure Torsion // Diagnostics, Resource and Mechanics of materials and structures. - 2015. - Iss. 5. - P. 118-132. - URL: http://dream-journal.org/issues/2015-5/2015-5_52.html (accessed: 30.10.2017).

2. Natural and artificial aging of bronzes used as matrix in Nb3Sn-base composites / T. P. Krinitsina, E. N. Popova, S. V. Sudareva, E. P. Romanov, A. D. Nikulin, A. K. Shikov, A. Y. Vorobyova // Fizika metallov i metallovedenie. - 1991. - No. 11. - P. 90-98.

3. Tsubakino H. Discontinuous precipitation in $\mathrm{Cu}-\mathrm{Sn}$ alloy // Metallography. - 1984. Vol. 17, no. 4. - P. 371-382. - DOI: 10.1016/0026-0800(84)90074-0

4. Williams D. B., Butler E. P. Grain boundary discontinuous precipitation reaction // International Metals Reviews. - 1981. - Vol. 26, iss. 1. - P. 153-183. - DOI: 10.1179/imtr.1981.26.1.153

5. Сучков Д. И. Медь и ее сплавы. - М. : Металлургия, 1967. - С. 104-176.

6. Установление соответствия между степенью деформации, твердостью и размерами элементов структуры железа и конструкционных сталей при большой пластической деформации различными способами / М. В. Дегтярев, Т. И. Чащухина, Л. М. Воронова, В. И. Копылов // Физическая мезомеханика. - 2013. - Т. 16, № 6. - С. 71-80.

7. Вишняков Я. Д. Дефекты упаковки в кристаллической структуре // М. : Металлургия, 1970. $-66 \mathrm{c}$.

8. Nanostructurization of $\mathrm{Nb}$ by high-pressure torsion in liquid nitrogen and the thermal stability of the structure obtained / V. V. Popov, E. N. Popova, A. V. Stolbovskii, V. P. Pilyugin, N. K. Arkhipova // The Physics of Metals and Metallography. - 2012. - Vol. 113, no. 3. P. 295-301. - DOI: 10.1134/S0031918X1203009X

9. Structure and Properties of Grain Boundaries in Submicrocrystalline W Obtained By Severe Plastic Deformation / V. V. Popov, R. Z. Valiev, E. N. Popova, A. V. Sergeev, A. V. Stolbovsky, V. U. Kazihanov // Defect and Diffusion Forum. - 2009. - Vol. 283-286. -P. 629-639. DOI: $10.4028 /$ www.scientific.net/DDF.283-286.629

10. Deformation and dynamic recrystallization in copper at different deformation rates in Bridgman anvils / T. I. Chashchukhina, L. M. Voronova, M. V. Degtyarev, D. K. Pokryshkina // The Physics of Metals and Metallography. - 2011. - Vol. 111. - P. 304-313. DOI: $10.1134 / \mathrm{S} 0031918 X 11020049$ 